\title{
Investigation on the Methaemoglobin Concentration of Three Human Erythrocyte Genotypes Infected With Plasmodium falciparum.
}

\author{
${ }^{1}$ CHIKEZIE, P. C.; ${ }^{1}$ CHIKEZIE, C. M.; ${ }^{2}$ UWAKWE, A. A.; ${ }^{2}$ MONAGO, C. C. \\ ${ }^{I}$ Department of Biochemistry, Imo State University, Owerri, Imo State, Nigeria. Phone: +2348038935327. \\ ${ }^{2}$ Department of Biochemistry, University of Port-Harcourt, Port-Harcourt, Rivers State, Nigeria.
}

\begin{abstract}
Investigation to ascertain the levels of methaemoglobin concentration of three human erythrocyte genotypes (HbAA, HbAS and HbSS) obtained from apparently healthy and clinically confirmed malarious subjects/volunteers was carried out. Spectrophotometric method was used for the determination of erythrocyte methaemoglobin concentration. The mean $\left({ }_{-}\right.$S.D $)$methaemoglobin concentration, expressed as percentage (Met.Hb $\%)$ of total haemoglobin concentration of three erythrocyte was in the order: $\mathrm{HbAA}<\mathrm{HbAS}<\mathrm{HbSS}$. There was no significant difference $(p>0.05)$ between methaemoglobin concentrations of HbAA and HbAS erythrocyte of nonmalarious human subjects/volunteers. Erythrocyte obtained from blood sample of malarious human subjects/volunteers exhibited significantly $(p<0.05)$ higher levels of methaemoglobin concentrations than those of non-malarious individuals, irrespective of their genotype and gender. In a similar manner, $P$. falciparum infected erythrocyte of malarious male individuals contained significantly $(p<0.05)$ higher methaemoglobin concentration than the female group. Furthermore, with exception of HbAS erythrocytes, the other two red cell genotypes (HbAA and $\mathrm{HbSS}$ ) showed significant difference $(\mathrm{p}<0.05)$ in methaemoglobin content between malarious male and female subjects/volunteers. The study suggests that erythrocyte methaemoglobin evaluation might be a reliable biochemical marker and possess promising rational for diagnostic potential in malaria. @ JASEM
\end{abstract}

Methaemoglobinemia is an abnormally high plasma concentration of haemoglobin in which the haem iron is in the ferric state $\left(\mathrm{Fe}^{3+}\right)$. Cyanotic presentation is typically observed at methaemoglobin concentration greater than fifteen percent $(15.0 \%)$ of total haemoglobin concentration. It is often one of the earliest clinical presentation/evidence of methaemoglobinemia (Methaemoglobinemia, 1998, Hopkins, 2000, Mallory 2003). During intraerythrocytic development, $P$. falciparum ingests large amount of haemoglobin to meet its nutrient requirement (Liu et al., 1992) and to maintain osmotic stability within the host cell (Lew et al., 2003).Specifically, the malaria parasite ingests 25 to $80 \%$ of erythrocyte haemoglobin (Goldberg, 1993, Roth et al., 1986). Haemoglobin molecules, taken up by endocytosis undergo hydrolysis in the parasite's digestive acidic vacuole called the food vacuole.

Malaria parasites are particularly vulnerable to oxidative stress during the erythrocytic life stages (Hunt and Stocker, 1990; Simoes et al., 1992; Muller et al., 2003; Becker et al., 2004). This is not surprising as the parasites live in a pro-oxidant environment that contains oxygen and iron, the key prerequisite for the formation of reactive oxygen species (ROS) via the Fenton reaction. Haemoglobin that is taken up by the parasites into their acid food vacuole leads to the spontaneous oxidation of $\mathrm{Fe}^{2+}$ to $\mathrm{Fe}^{3+}$ and the formation of superoxide anions. This combination inevitably leads to the generation of hydrogen peroxide and subsequently hydroxyl radicals, both highly reactive and toxic oxygen intermediates (Liochev and Fridovich, 1999). Therefore, haemoglobin metabolism is inextricably connected with the pathophysiology of malaria disease. The present study is focused on the possible utilization of erythrocyte methaemoglobin concentration as a parameter in malaria diagnosis amongst three human erythrocyte genotypes.

\section{MATERIALS AND METHODS: \\ Selection of Volunteers/ Experimental Design:}

Non-Malarious Subjects/Volunteers (Control Group): $\quad$ Seventy-(70) male $(61-73 \mathrm{~kg})$ subjects/volunteers of confirmed HbAA (25), HbAS (25) and HbSS (20) genotypes between the ages of 20-28years enrolled for this study. The female category was made up of forty-two (42) subjects/volunteers (55-69kg); HbAA (20), HbAS (20) and HbSS (12). Their age bracket was between 18-27years.

Malarious Subjects/Volunteers (Test Group): Sixty-one (61) male (59-79kg) subjects/volunteers HbAA (24), HbAS (25) and HbSS (12) and fortythree (43) female $(55-76 \mathrm{~kg})$ subjects/volunteers, HbAA (15), HbAS (15) and HbSS (13) enrolled for this study. The male and female subjects were between the age brackets of 21-34 and 20-25 years respectively.

Ethics: The institutional review board of the Department of Biochemistry, University of Port Harcourt, Port Harcourt, Nigeria, granted approval for this study and all subjects/ volunteers involved signed an informed consent form. This conducted study was in accordance with the ethical principles that have their origins in the Declaration of Helsinki. Individuals drawn were from Imo State University, Owerri, Nigeria and environs. The research protocols 
were in collaboration with registered and specialized clinics and medical laboratories.

Collection of Blood Samples/Preparation of Erythrocyte Haemolysate: Five milliliters $(5.0 \mathrm{ml})$ of venous blood obtained from the volunteers by venipuncture was stored in EDTA anticoagulant tubes. Blood of HbSS genotype and malarious blood samples were from patients attending clinics at the Federal Medical Center (FMC), Imo State University Teaching Hospital (IMSUTH), Orlu, St.John Clinic / Medical Diagnostic Laboratories, Avigram Medical Diagnostic Laboratories, and Qualitech Medical Diagnostic Laboratories. These centers are located in Owerri, Imo State, Nigeria. The erythrocytes were washed by methods as described by Tsakiris et al.,(2005). Within 2hrs of collection of blood samples, portions of $1.0 \mathrm{ml}$ of the samples were introduced into centrifuge test tubes containing $3.0 \mathrm{ml}$ of buffer solution $\mathrm{pH}=7.4$ : $250 \mathrm{mM}$ tris (hydroxyl methyl) amino ethane-HCl(Tris$\mathrm{HCl}$ )/140mMNaCl/I.0mMMgCl$/ 2 / 10 \mathrm{mMglucose}$ ).

The erythrocytes were separated from plasma by centrifugation at $1200 \mathrm{xg}$ for $10 \mathrm{mins}$, washed three times by three similar centrifugations with the buffer solution. The erythrocytes re-suspended in $1.0 \mathrm{ml}$ of this buffer were stored at $4^{0} \mathrm{C}$. The washed erythrocytes were lysed by freezing/thawing as described by Galbraith and Watts, (1980) and Kamber et al., (1984). The erythrocyte haemolysate was used for the determination of methaemoglobin concentration.

Determination of Methaemoglobin Concentration of Erythrocyte Lysate: Determination of methaemoglobin content of red cell lysate was by modification of the method of Evelyn and Malloy, (1938), as described by Akomopong et al., (2000). A total of $400 \mu \mathrm{l}$ of $0.5 \mathrm{M}$ Phosphate buffer ( $\mathrm{pH} 6.5$ ) was added to $600 \mu \mathrm{l}$ of the cell lysate, and the mixture was centrifuged at $16,000 \mathrm{~g}$ for 5 minutes to sediment debris. A total of $700 \mu \mathrm{l}$ of the supernatant fraction was used to measure the absorbance at $\lambda_{\max }=630 \mathrm{~nm}$ (the absorbance maximum for methaemoglobin), and the reading was recorded as SI. A total of $50 \mu \mathrm{l}$ of 10 gpercentageKCN was added, and after 5 minutes at room temperature $\left(24^{0} \mathrm{C}\right)$, a second reading $(\mathrm{S} 2)$ was recorded. $\mathrm{KCN}$ converts methaemoglobin to cyanomethaemoglobin, which does not absorb at $630 \mathrm{~nm}$; hence, the difference between absorbance readings $\mathrm{S} 1$ and $\mathrm{S} 2$ represents the absorbance due to methaemoglobin.

To measure total hemoglobin levels, all of the hemoglobin was converted to methaemoglobin, the absorbance of the sample at $\lambda_{\max }=630 \mathrm{~nm}$ was recorded, and then $\mathrm{KCN}$ was added to form cyanomethaemoglobin. Specifically, $70 \mu \mathrm{l}$ of the supernatant fraction was diluted 10-fold into $600 \mu \mathrm{l}$ of $0.1 \mathrm{M}$ phosphate buffer (pH6.5). Next, 30 $\mu$ l of freshly prepared $20 \mathrm{~g} \% \mathrm{~K}_{3} \mathrm{Fe}(\mathrm{CN})_{6}$ was added and incubated for 5minutes at room temperature $\left(24^{\circ} \mathrm{C}\right)$ and an initial reading (T1) was recorded. A total of $50 \mu \mathrm{l}$ of $10 \% \mathrm{KCN}$ was subsequently added, and a second reading (T2) was recorded. The percent methaemoglobin in the sample was calculated as [100(S1-S2)] / [10(T1-T2)].

Statistical Analyses: The experiments were designed in a completely randomized method and data collected were analyzed by the analysis of variance procedure while treatment means were separated by the Least Significance Difference (LSD) incorporated in the Statistical Analysis System (SAS) package of 9.1 version,(2006).

\section{RESULTS AND DISCUSSION}

The mean ( expressed as percentage (Met.Hb \%) of total haemoglobin concentration of three erythrocyte genotypes (HbAA, $\mathrm{HbAS}$ and $\mathrm{HbSS}$ ) of blood samples obtained from non-malarious and malarious human subjects/volunteers is presented in Table 1 below.

Table 1: Methaemoglobin Concentration (MetHb\%) of Human Erythrocyte Haemolysate:

\begin{tabular}{lll}
\hline Genotype/Gender & \multicolumn{2}{c}{$($ Met.Hb\%) $(\mathrm{X}+/-\mathrm{S} . \mathrm{D})$} \\
\hline & Non-malarious & Malarious \\
1).HbAA & & \\
Male $\left(\mathrm{n}=15^{\mathrm{NM}} ; 15^{\mathrm{M}}\right)$ & $1.48 \pm 0.14^{\mathrm{a}}$ & $14.07 \pm 2.56^{\mathrm{b}}$ \\
Female $\left(\mathrm{n} 15=^{\mathrm{NM}} ; 15^{\mathrm{M}}\right)$ & $1.51 \pm 0.08^{\mathrm{a}}$ & $11.90 \pm 1.48^{\mathrm{a}}$ \\
2).HbAS & & \\
Male $\left(\mathrm{n}=15^{\mathrm{NM} ;} 15^{\mathrm{M}}\right)$ & $1.45 \pm 0.13^{\mathrm{a}}$ & $8.27 \pm 2.41^{\mathrm{a}}$ \\
Female $\left(\mathrm{n}=14^{\mathrm{NM}} ; 15^{\mathrm{M}}\right)$ & $1.50 \pm 0.11^{\mathrm{a}}$ & $8.25 \pm 1.86^{\mathrm{a}}$ \\
\hline & & \\
3).HbSS & $2.50 \pm 0.43^{\mathrm{b}}$ & $14.78 \pm 2.45^{\mathrm{a}}$ \\
Male $\left(\mathrm{n}=13^{\mathrm{NM}} ; 15^{\mathrm{M}}\right)$ & $2.94 \pm 0.35^{\mathrm{a}}$ & $14.68 \pm 2.50^{\mathrm{b}}$. \\
Female $\left(\mathrm{n}=13^{\mathrm{NM} ;} 12^{\mathrm{M}}\right)$ & & \\
\hline
\end{tabular}

$\mathrm{M}$ and $\mathrm{NM}=$ number of malarious and non-malaroius blood samples respectively. Means in the column with the same letter are not significantly different at $p<0.05$ according to LSD.

A cursory look at Table 1 showed erythrocyte obtained from blood sample of malarious human subjects/volunteers exhibited significantly $(p<0.05)$ higher levels of methaemoglobin concentrations than those of non-malarious individuals, irrespective of their genotype and gender. There was no significant difference $(p>0.05)$ between methaemoglobin concentrations of $\mathrm{HbAA}$ and $\mathrm{HbAS}$ erythrocyte of non-malarious human subjects/volunteers. On the contrary, $P$. falciparum infected erythrocyte of malarious male individuals contained higher methaemoglobin concentration than the female group. Furthermore, with exception of $\mathrm{HbAS}$ erythrocytes, the other two red cell genotypes (HbAA and $\mathrm{HbSS})$ showed significant difference $(\mathrm{p}<0.05)$ in methaemoglobin content between malarious male and female subjects/volunteers. In addition, erythrocyte 
genotype (HbSS) obtained from female individuals exhibited significantly $(p<0.05)$ higher levels of methaemoglobin concentration than those of the male counterpart. An overview of the results presented in Table 1 showed that methaemoglobin concentrations of both non-malarious and malarious human subjects/volunteers ranged between $1.45 \pm 0.13 \%$ and $14.78 \pm 2.45 \%$. The determination of erythrocyte methaemoglobin concentration as a toxic endpoint in chemical poisoning and pathologic conditions showed reliability and reproducibility in clinical diagnostic procedures (Hopkins, 2000; Bradberry, 2003; Uko et al., 2007). This present study reported significant $(p<0.05)$ elevation of methaemoglobin concentrations of human subjects/volunteers infected with malaria, irrespective of their genotype (Table 1). This observation was in agreement with the reports of Uko et al., (2007) who demonstrated high level of methaemoglobin in subjects with severe malaria parasitaemia and suggested routine estimation of methaemoglobin in malaria for clinical evaluation of patients. Furthermore, Anstey et al., (1996) documented elevated methaemoglobin concentration of Tanzanian children with severe and uncomplicated malaria. In the same vein, the present report was in concordance with observations of Friedman et al., (1979). These authors showed that cultures with high levels of parasitemia contained between 3 to 10 times more methaemoglobin than those with low levels of parasitemia. Akompong et al., (1999), found isolated malarial parasites contained between 20 to 42 percent of methaemoglobin concentration. In contrast, uninfected red blood cells presented between 0.5 to 1.0 percent of methaemoglobin. Therefore, they suggested the parasite induced raised levels of methaemoglobin in infected erythrocyte. In addition, these authors noted that increased methaemoglobin in malarial infection was a reflection of rapid oxidation of haemoglobin ingested by the parasites to methaemoglobin. It worthwhile to recall that raised oxidant levels compounded by compromised activity of erythrocyte redox enzymes further exacerbate the tendency towards spontaneous oxidation of haemoglobin molecule in parasitized red cells. De Rosa et al., (2003), used methaemoglobin levels as a marker molecule for the presence of nitrogen oxide generated by parasite as consequence of their metabolism (Clark et al., 1991). All these were pointers to the fact that parasitized erythrocytes exhibited raised levels of methaemoglobin. Similar to the reports of Neupane et al., (2008), the decreasing methaemoglobin concentrations with time after administration of the five antimalarial drugs suggest decreasing levels of ROS due to the killing of the parasites. Relationship exists between levels of parasitemia and levels of ROS production (Friedman et al., 1979; Uko et al., 2007; Neupane et al., 2008).
The pattern of variability of basal erythrocyte methaemoglobin concentrations amongst nonmalarious human subjects/volunteers showed that the dysfunctional red cell of HbSS genotype was significantly $(p<0.05)$ higher than the normal one, HbAA (Table 1). This result conformed to earlier reports by Tamer et al., (2000). They noted that the primary reason for the relatively raised concentration of oxidized haemoglobin (methaemoglobin) in HbSS erythrocytes was higher production of superoxide ion by these erythrocytes compared to those of HbAA and $\mathrm{HbAS}$ erythrocytes. Furthermore, erythrocyte endogenous oxidant (haemin) showed higher levels in HbSS than HbAA erythrocytes. Haemin has a profound capacity to activate certain erythrocyte redox enzymes e.g. NADH methaemoglobin reductase (Uwakwe, 1991) and its presence at high concentration is attributable to the high level of haemolytic phenomenon peculiar to this haemoglobin variant cell (Orjih et al., 1985).

\section{REFERENCE}

Akomopong,T; Ghori, $\mathrm{N}$ and Haldar,K(2000). In vitro activity of riboflavin against the human malaria parasite Plasmodium falciparum. Antimicrobial Agents and Chemotherapy. Vol.44. no1.88-96.

Anstey, N.M; Hassanali, M.Y; Mlalasi, J; Manyenga, D and Mwaikambo, E.D (1996). Elevated levels of methaemoglobin in Tanzanian children with severe and uncomplicated malaria. Trans. R. Soc. Trop. Med. Hyg. Vol. 90 No2: 147-151.

Becker, K; Tilley, L; Vennerstrom, J.L; Roberts, D; Rogerson, S., and Ginsburg, H. (2004).Oxidative stress in malaria parasite infected erythrocytes: host - parasite interactions. Int. J. Parasitol. 34: 163 -189.

Bradberry, S.M (2003). Occupational methaemoglobinemia. Mechanisms of production, features, diagnosis and management including the use of methylene blue. Toxicol. Rev. 22(1): 13-27.

Clark, I.A; Rockett, K.A; Cowden, W.B (1991). Proposed link between cytokines, nitric acid and human cerebral malaria. Parasitol. Today. 7:205207.

De Rosa, M; Zarrilli, S; Paesano, L; Carbone, U; Boggia, B; Petretta, M; Maisto, A; Cimmino, F; Puca, G; Colao, A and Lombardi, G. (2003).Traffic pollutants affect fertility in men. Hum. Reprod.; 18: 1055 -1061. 
Evelyn,K and Malloy,H.(1938). Micro determination of oxyhaemoglobin, methaemoglobin and sulfhaemoglobin in a single sample of blood. J.Biol.Chem.126:655-662.

Friedman, M.J; Roth, E.F; Nagel, R.L and Trager, W.(1979). Plasmodium falciparum: physiologic interaction with human sickle cell. Exp. Parasitol. 47:73-80.

Goldberg, D.E.(1993).Haemoglobin degradation in Plasmodium-infected red blood cells. Semin. Cell Biol. 4: $355-361$.

Hopkins, U. (2000): Methaemoglobinemia. J. Tox. Clin. Tox. 36:6-12.

Hunt, N.H and Stocker, R.(1990).Oxidative stress and the redox status of malaria - infected erythrocytes. Blood Cells. 16: 499-526.

Liochev, S.I and Fridovich, I.(1999).Superoxide and iron: partners in crime. IUBMB Life. 48:157161.

Liu, S; Zhang, P; Ji, X; Johnson, W.W; Gilliland, G.L and Armstrong R.N. (1992).Contribution of tyrosine to the catalytic mechanism of isoenzyme of glutathione S-transferase. J. Biol. Chem. 267: 4296-4299.

Mallory,M.(2003).Methaemoglobinemia.Utox.Updat e.5:1-2. http://www.uuhsc.utah.edu/poison.

Methaemoglobinemia.(1998).http://www.mc.vanderb ilt.edu/peds/peds/pidl/hemeon/metheme.htm.

Muller, S; Lieban, E; Walter, R.D and Krauth Siegel, R.L.(2003).Thiol-based redox mechanism of protozoan parasites. Trends Parasitol. 19: 320 - 328.
Neupane, D.P; Majhi, S; Chandra, L; Rijal, S and Baral, N. (2008). Erythrocyte glutathione status in human visceral Leishmaniasis. Indian. J. Clin. Biochem. Vol. 23(1): 95-97.

Orjih, A.U; Cheuli, R and Fitch, C.D. (1985). Toxic heme in sickle cells: An explanation for death of malaria parasites. Am. J. Trop. Med. Hyg. 34(2): 223-227.

Roth, E.F, Jr; Brotman, D.S; Vanderberg and Schulman, S. (1986).Material pigmentdependent error in the estimation of haemoglobin content in Plasmodium falciparum-infected red cell: implications for metabolic and biochemical studies of the erythrocytic phases of malaria. Am. J. Trop. Med. Hyg. 35: 906 - 911.

Simoes, A.P; Van den Berg, J.J; Roelofsen, B and Op den Kamp, J.A. (1992).Lipid peroxidation in Plasmodium falciparum - parasitized human erythrocytes. Arch. Biochem. Biophys. 298: 651652.

Statistical Analysis System (SAS) package of 9.1 version,(2006).

Tamer, L; Gurbuz, P; Guzide, Y; Birol, G and Fikri, B. (2000). Erythrocyte membrane Na+$\mathrm{K}+/ \mathrm{Mg}++$ and $\mathrm{Ca}++/ \mathrm{Mg}++$ Adenosine 5' Triphosphate in patients with sickle cell anaemia. Turk. J. Haematol. 17(1):23-26.

Uko, E.K; Udoka, A.E and Etukudoh, M.H. (2007). Methaemoglobin profile in malaria infected children in Calabar. Niger. J. Med. 12(2): 94- 97.

Uwakwe, A.A. (1991): Activities of some redox enzymes from different human red blood cell genotype. Ph.D Thesis, University of Port Harcourt, Port Harcourt, Nigeria. 